\title{
Cross-sectional study of chromosomal aberrations and immunologic factors in Iraqi couples with recurrent pregnancy loss
}

\author{
Doaa A. Khamees ${ }^{1}$, Mushtak T. S. Al-Ouqaili ${ }^{\text {Corresp. } 1}$ \\ ${ }^{1}$ Department of Microbiology, College of Medicine, University of Anbar, Al-Anbar Governorate, Ramadi, Iraq \\ Corresponding Author: Mushtak T. S. Al-Ouqaili \\ Email address: mushtak.t.neda@gmail.com
}

Background. Parental chromosomal aberrations are important causes of recurrent pregnancy loss (RPL). Some immunological factors such as antiphospholipid antibodies and interleukin-6 (IL-6) also contribute to this complication. The aim of this study was to determine the frequency of chromosomal abnormalities and to evaluate some of the immunological factors in couples with RPL from different cities in Iraq. Methods. This study was conducted on 25 couples (50 individuals) who had more than two first trimester abortions in the past and 25 healthy females as controls. Karyotyping was performed on peripheral blood of all participants. Anticardiolipin (IgG and IgM), antiphosopholipid (IgG and IgM), lupus anticoagulant, and IL-6 were assayed. Data were analyzed using appropriate statistical tests. Results. Chromosomal abnormalities were found in $28.0 \%$ (n $=7 / 25)$ of RPL couples. Of these $5(10.0 \%)$ were female and $2(4.0 \%)$ were male. The types of structural abnormalities were as follows: $45, X X, t(21 ; 21) ; 45, X X$, rob $(14,15)$; 46, XX, add (21)(p13); $46 \mathrm{XY}$, add (21)(p13); 46, XX, 21ps+; 46, XY, per inv (9) (p11q12) and $45, X X, t(13 q, 13 q)$. No chromosomal abnormalities were found in the control group. Also, no significant differences were found in the immunological parameters of the couples with RPL and the control group. In this study, karyotyping revealed a high number of chromosomal abnormalities associated with the RPL in Iraqi couples. Since identification of genetic causes of miscarriage is important for genetic counseling and educating couples about the risk of future pregnancies, it is recommended that conventional karyotyping be investigated in patients with RPL. 
1 Cross-sectional study of chromosomal aberrations and immunologic factors in Iraqi

2

3

4

5

6

7

8

9

10

11

12

13

14

15

16

17

18

19

12 couples with recurrent pregnancy loss

\section{Running title: Chromosomal aberrations in abortion}

Doaa A. Khamees ${ }^{1}$, Mushtak T. S. Al-Ouqaili ${ }^{*}$

${ }^{1}$ Department of Microbiology, College of Medicine, University of Anbar, Al-Anbar Governorate, Ramadi, Iraq

*Corresponding author: Mushtak T. S. Al-Ouqaili

Department of Microbiology, College of Medicine, University of Anbar, Al-Anbar Governorate, Ramadi, Iraq

Email: mushtak.t.neda@gmail.com

Tel: +9647830014212 


\section{Abstract}

Background. Parental chromosomal aberrations are important causes of recurrent pregnancy loss (RPL). Some immunological factors such as antiphospholipid antibodies and interleukin-6 (IL-6) also contribute to this complication. The aim of this study was to determine the frequency of chromosomal abnormalities and to evaluate some of the immunological factors in couples with RPL from different cities in Iraq.

Methods. This study was conducted on 25 couples (50 individuals) who had more than two first trimester abortions in the past and 25 healthy females as controls. Karyotyping was performed on peripheral blood of all participants. Anticardiolipin (IgG and $\operatorname{IgM})$, antiphosopholipid (IgG and $\operatorname{IgM}$ ), lupus anticoagulant, and IL-6 were assayed. Data were analyzed using appropriate statistical tests. Results. Chromosomal abnormalities were found in $28.0 \%(n=7 / 25)$ of RPL couples. Of these $5(10.0 \%)$ were female and $2(4.0 \%)$ were male. The types of structural abnormalities were as follows: 45, XX, t(21; 21); 45, XX, rob $(14,15) ; 46, \mathrm{XX}$, add (21)(p13); $46 \mathrm{XY}$, add (21)(p13); 46, XX, 21ps+; 46, XY, per inv (9) (p11q12) and 45, XX, t(13q, 13q). No chromosomal abnormalities were found in the control group. Also, no significant differences were found in the in immunological parameters of the couples with RPL and the control group. In this study, karyotyping revealed a high number of chromosomal abnormalities associated with the RPL in Iraqi couples. Since identification of genetic causes of miscarriage is important for genetic counseling and educating couples about the risk of future pregnancies, it is recommended that conventional karyotyping be investigated in patients with RPL. 
42 Keywords: Chromosomal aberrations, Immunologic factors, Recurrent pregnancy loss, $43 \quad$ Karyotyping

\section{Introduction}

It is well documented that recurrent miscarriages are failures after implantation in natural conception. They are also known as recurrent pregnancy losses or habitual abortions [1]. Recurrent pregnancy loss (RPL) is one of the most common pregnancy complications and refers to the loss of a pregnancy before 20-24 weeks of gestation [2,3]. Determining the type of spontaneous abortion is a cornerstone in providing the most appropriate treatment [4]. Spontaneous abortion (SA) can be divided into inevitable abortion, threatened abortion,

56 incomplete abortion, septic abortion, missed abortion, complete abortion, and recurrent

57 spontaneous abortion (RSA) [5].

58 Early abortion is thought to be caused by fetal chromosomal abnormalities in $50 \%$ of the study 59 cases. The most important risk factors are advanced maternal age and women with a history of early pregnancy loss [6]. In Iraq, the problem of RSA has been found in a large number of women in recent years. The pattern of abnormal karyotypes and RSA has increased with the progression of environmental pollution in Iraq, which has been shown to have an impact on this situation $[7,8]$. It is well documented that cytogenetic studies include a variety of causes of abortion. 
65 It is generally accepted that the genetic factor plays a greater role in RSA. The genetic etiology 66 of pregnancy losses is described as: 1) type of chromosomal abnormalities 2) distribution of

67 chromosomal abnormalities compared to the number of pregnancy losses, 3) incidence of 68 chromosomal anomalies in recurrent miscarriages, and 4) fetal aneuploidy in recurrent

miscarriages [9]. Most pregnancy losses are caused by fetal chromosomal abnormalities [10]. Overall, $50 \%$ to $60 \%$ of all pregnancy losses are caused by chromosomal aberrations and cytogenetic analysis is very important to make the diagnosis and detect genetic involvement in the family. Cytogenetic tests should also be recommended in couples with RSA because the result of these tests can provide important information for genetic counseling $[11,12]$.

On the other hand, about 15 to $20 \%$ of women suffering from recurrent miscarriage have antiphospholipid antibody syndrome (APS). There are heterogeneous types of antiphospholipid antibodies including lupus anticoagulant and anticardiolipin (IgG or $\operatorname{IgM}$ ) which attack the phospholipids found in the membranes of endothelial cells, platelets, and other cells of the coagulation cascade. In addition to persistent antiphospholipid antibodies (APLs), pregnancy complications, thrombosis, recurrent abortions, and occasionally thrombocytopenia occur in this autoimmune disorder [13]. The anti-inflammatory cytokine, interleukin-6 (IL-6) has also been studied for its role in normal pregnancy and pregnancy-related complications. A constitutive level of this cytokine is detected in uterine tissues during both gestation and pregnancy. Nevertheless,its specific function in the different compartments of the uterus is still unclear [14]. It is believed that IL-6 is one of the factors involved in the pathology of miscarriage. In a previous study, the levels of IL-6 in the blood serum of patients with miscarriage were significantly higher than those in normal pregnancy [15]. 
87 To date, there are few studies that can provide an overview of the prevalence of chromosomal

88

89

90

91

92

93

94

95

96

97

98 abnormalities in women with RPL in Iraq, and many of them have not evaluated the immunological factors involved in this process. Therefore, the aim of this study was to investigate the chromosomal aberrations or abnormalities in Iraqi female patients with RPL using cytogenetic analysis, to determine the type of chromosomal abnormalities either structural or numerical, and to investigate the level of some immunological factors in them.

\section{Materials and methods}

\section{Ethical statement}

This study was approved by the Medical Ethics Committee of the University of Anbar, Al-Anbar Governorate, Ramadi, Iraq (approval number 88, July, 25, 2021) in accordance with the Declaration of Helsinki. Written informed consents were obtained from all study participants.

\section{Selection of study patients and healthy volunteers}

This descriptive cross-sectional study was conducted on 25 couples (50 individuals) who had a history of more than two first trimester abortion and 25 couples (50 healthy individuals) including women without a history of abortion and their partners as a control group. Couples referred to the Department of Chromosomes and Cancer Disease Department in in Baghdad, the capital of Iraq, and to private gynecological clinics in Ramadi, western Iraq, were recruited for this study. The participants were from different cities in Iraq. Miscarriage was diagnosed based on the patient's medical history and clinical examination. The women who had more than two miscarriages with different partners and women who had a living child, were excluded from this study. Other exclusion criteria were miscarriage related diseases such as infections, uterine abnormalities, diabetes mellitus, and hypertension. The inclusion criteria for the control group 
109 were couples with a normal pregnancy and those who had at least two healthy children. They

110 were also not allowed to have or suffer from any familial genetic abnormalities.

\section{Blood samples for cytogenetic analysis}

112 Peripheral venous blood samples were collected from all study participants between October 1132020 and May 2021. Blood samples $(5 \mathrm{ml})$ were collected in heparinized tubes using a $5 \mathrm{ml}$

114 syringe under aseptic conditions. The samples were cultured and evaluated for karyotyping.

\section{$115 \quad$ Karyotyping}

116 Chromosome culture was carried out by adding the blood sample to the artificial chromosome 117 media (Euroclone, Italy) which were ready to use media. After 70 hours of incubation at $37^{\circ} \mathrm{C}$, $118100 \mu \mathrm{l}$ of colcemid (Merck, Germany) was added. After a passage of 60 minutes, cells were 119 harvested (1500 rpm for 7 minutes). Then, a $0.075 \mathrm{M} \mathrm{KCl}$ solution was added, mixed and 120 incubated at $37^{\circ} \mathrm{C}$ for 15 minutes. After centrifugation (1500 rpm for 7 minutes), the hypotonic 121 supernatant was removed. Then, $10 \mathrm{ml}$ of cold fresh fixative solution (3:1 methanol: glacial acetic acid) was added dropwise to the cell pellet for the first $2 \mathrm{ml}$ to the cell pellet. Centrifugation was then performed and the supernatant was removed. The last two steps were repeated until a clear pellet was obtained. Finally, the obtained cells were dropped onto clean slides and stained with Giemsa [16]. Chromosomal status was analyzed using the MetaClass Karyotyping apparatus (MICROPTIC

127 S.L., Spain) and a fluorescence microscope (Euromex, Netherland). Metaphases and 128 chromosome preparations from peripheral blood cultures were examined according to standard 129 cytogenetic protocols. Cytogenetic analysis was performed by G-banding. Twenty metaphases were analyzed in all participants. In some cases, especially when abnormalities and mosaicism 
131 were suspected, the analysis was extended to 50 metaphases. Chromosomal abnormalities were

132 reported according to the International System of Human Cytogenetic Nomenclature [17].

133 Immunological assays

134 Immunological parameters, including anticardiolipin (IgG and IgM) and antiphosopholipid (IgG 135 and $\operatorname{IgM}$ ) were evaluated by enzyme-linked immunosorbent assay (ELISA) (Demeditec 136 Diagnostics, Germany) in all studied females according to the manufacturer's instructions. The 137 results were considered positive if the cut-off values of anticardiolipin IgG and IgM were more 138 than $10 \mathrm{GPH}-\mathrm{U} / \mathrm{ml}$ and $7 \mathrm{MPH}-\mathrm{U} / \mathrm{ml}$, respectively. The same values were also assumed for anti139 phospholipid IgG and IgM. IL-6 was also assayed for all females by ELISA technique according to the procedure of the manufacturing kit, Elecsys IL-6, Roche Diagnostic, Germany. The normal reference range was up to $7 \mathrm{pg} / \mathrm{ml}$. Lupus anticoagulant assay was performed according to procedure laid down by the manufacturing instructions kit, Stago, France, and the specific instrument, Genru CA45, China. The normal values for this test ranged from 31 to 41 seconds.

\section{Data analysis}

All variables were analyzed using SPSS software version 22 (Armonk, NY, USA). Chi-square test was used to compare the studied groups. The level of $P<0.05$ was considered significant $[18,19]$.

\section{Results}

In this study, the age of the 25 women with a normal delivered pregnancy ranged from 19 to 37

150 years with a mean \pm SD: $26.36 \pm 5.69$ years. The age of the 25 study women with a history of 151 RPL ranged from 17 to 43 years, with a mean \pm SD: $31.68 \pm 7.53$ years. The distribution of study 152 participants (patients with RPL and healthy control group) according to their age is shown in Fig 153 1. The distribution of healthy and RPL women with $\leq 28$ years was significantly different $(P$ - 
154 value 0.0465$)$, while it was not significantly different among participants with $>28$ years $(P$ -

155 value $>0.05)$. . There was a direct significant correlation between the number of recurrent

156 pregnancy losses and the age of the female partners. In other meanings, the likelihood of abortion

157 increases with age, with a moderate positive significant correlation with a value of 0.565 and a

$158 \quad P$-value $=0.03$ as shown in Fig 2.

159 Cytogenetic analysis of paternal karyotyping was performed in all 100 studied participants. No 160 chromosomal abnormalities were found in the females and their partners in the control group.

161 However, chromosomal abnormalities were found in $28.0 \%(n=7 / 25)$ of the RPL couples. Of 162 these, $5(10.0 \%)$ were female and $2(4.0 \%)$ were male. All of these chromosomal abnormalities 163 were structural and no numerical chromosomal abnormalities were detected. In one case, both 164 the wife and her husband had structural abnormalities. The detailed abnormalities are 165 summarized in Table 1. The types of structural abnormalities cases were as follows: 45, XX, $166 \operatorname{rob}(21 ; 21) ; 45, \mathrm{XX}, \operatorname{rob}(14 ; 15) ; 46, \mathrm{XX}, \operatorname{add}(21)(\mathrm{p} 13) ; 46, \mathrm{XY}, \operatorname{add}(21)(\mathrm{p} 13) ; 46, \mathrm{XX}, 21 \mathrm{ps}+$; 167 46, XY, inv(9)(p11q12); and 45, XX, rob(13;13).

168 The complete descriptions of all cases with the chromosomal abnormalities with a specific 169 karyotype for each case are represented in the following Fig (3-9).

170 Case 1 was a 36-year-old female with a history of two babies born with Down syndrome and 171 repeated miscarriages (three abortion in the first trimester). The karyotype was 45, XX, rob (21; 172 21) indicating a Robertsonian translocation of chromosome 21 (Fig 3). The karyotype of her 173 husband (38 years) was normal $(46, \mathrm{XY})$.

174 Case 2 was a 33-year-old female with a history of recurrent pregnancy loss (three abortion in 175 the $1^{\text {st }}$ trimester). The karyotype was $45, \mathrm{XX}$, rob $(14 ; 15)$ consistent with a Robertsonian 
176 translocation between the long arm of chromosome 14 and the long arm of chromosome 15 (Fig

177 4). The karyotype of her husband (35 years) was normal (46, XY).

178 Case 3 was a couple referred for chromosomal analysis because three pregnancies had been

179 aborted in the first trimester. The karyotype of the male (21 years) as shown in Fig 5 revealed 180 the presence of additional material attached to band $21 \mathrm{p} 13$ as follows: $46, \mathrm{XY}$, add (21)(p13).

181 On the other hand, the karyotype of his wife (18 years) showed the same structural changes 182 observed in the husband: 46, XX, add (21)(p13) (Fig 6).

183 Case 4 was a 17-years-old female with a history of four repeated miscarriages (four abortion in the first trimester). Her karyotype was $46, \mathrm{XX}, 21 \mathrm{ps}+$ consistent with an increase in the length of satellite on the short arm of chromosome 21 (Fig 7). Her husband's (28 years) karyotype was normal $(46, \mathrm{XY})$.

Case 5 was 43 -years-old female with a history of three recurrent miscarriages (three abortion in the first trimester). Her karyotype was normal (46, XX), while her husband had an abnormal karyotype which was 46, XY, per inv(9)(p11q12). This karyotype was a pericentric inversion of chromosome 9 which may be a normal variant in humans (Fig 8).

191 Case 6 was a 37-years-old female with history of four recurrent miscarriages (four abortion in the first trimester). Her karyotype was $45, \mathrm{XX}, \operatorname{rob}(13 ; 13)$. This case involved a balanced Robertsonian translocation between the long arms of both copies of chromosome 13 (Fig 9).

\section{Immunological parameters}

The distribution of antiphospholipid (IgG, $\operatorname{IgM})$, anticardiolipin (IgG, IgM), lupus anticoagulant, and IL-6 levels in the female participants with RPL are shown in Table 2. normal ranges and no test was abnormal. As shown in Table 3, no statistical differences were 
199 found in the immunological factors of the study between the PRL patients and the healthy female 200 subjects $(P$-value $>0.05)$.

201 The results of RPL females revealed that the mean \pm standard deviation of anti-phospholipid 202 (IgG and IgM), anti-cardiolipin (IgG and IgM), lupus anticoagulant, and IL-6 were 0.37 \pm 0.209 , $203 \quad 0.36 \pm 0.188,0.22 \pm 0.122,0.35 \pm 0.15,31.36 \pm 2.48$, and $1.58 \pm 0.38$, respectively (Table 4 and 204 Fig 10). Discussion

205 It is well documented that recurrent pregnancy loss is a multifactorial condition with many 206 causes including parental genetic problem, uterine abnormalities, immunologic disorders, 207 hematologic disorders, hormonal imbalances, and environmental factors. Spontaneous miscarriage in the first trimester is mainly due to chromosomal anomalies, such as single gene mutations, chromosomal instability and sperm chromosomal abnormalities, which explain idiopathic reproductive loss [20,21].

Several studies have been carried out to determine the prevalence of chromosomal aberrations among women with spontaneous miscarriage. However, this issue is rarely addressed in Iraqi couples with RPL. In this study, chromosomal abnormalities were detected in $24.0 \%(n=6 / 25)$ of Iraqi couples with RPL. Moreover, chromosomal abnormalities were higher in females $(10.0 \%)$ than in males $(4.0 \%)$. In a previous study by Hanif et al. [22] from Pakistan, 28.1\% of the studied couples with recurrent spontaneous miscarriages had chromosome abnormalities which was nearly eqal to this study. They also reported chromosomal abnormalities in $55.6 \%$ of

218 females and $44.4 \%$ of males, indicating almost equal prevalence in both genders, which was in contrast to the current research. In a review article by Marqui [23], the percentage of chromosomal abnormalities in couples with recurrent miscarriages varied from $1.23 \%$ to $12.0 \%$. He claimed that in almost $70.0 \%$ of the 
222 studies, chromosomal abnormalities were above 50\%. In a study from Iran by Narooie-Nejad et

223 al. [24], chromosomal abnormalities were detected in $6.7 \%$ of 30 couples with a history of

224 recurrent miscarriage, which was lower than our findings. They detected the chromosomal

225 abnormalities in 2 females, while no males had these abnormalities, which was contrary to the

226 current study. In another research from Iran by Ghazaey et al. [25], 11.7\% of 728 couples with a

227 history of recurrent miscarriage had abnormal karyotypes. Moreover,the number of females (n

$228=48)$ with chromosomal aberrations was higher than that of males $(n=37)$, which was consistent

229 with the current study. The prevalence of chromosomal aberrations in the current study was

230 higher than the research by the Fan et al. [26] from China. They reported a prevalence rate of

232 a higher incidence rate of chromosomal abnormalities in females than in males, which was in

233 agreement with our findings. Also, Elkarhat et al. [27] from Morocco reported a lower

234 prevalence rate of chromosomal abnormalities (11.0\%) in 627 couples with RSA compared to

235 the current study. Nevertheless, in line with our findings, the incidence rate of chromosomal

236 aberrations was higher in women (7.5\%) than men (3.5\%) [27]. The single ovum produced each

237 month is a possible reason for the higher chromosomal abnormality in the female partner. Nature

238 then selects against the abnormal gametes, as millions of sperm are released with each expulsion

$239 \quad[26]$.

240 Despite the clear definition of RPL as the natural termination of two or more consecutive

241 pregnancies before the fetus is capable of external life (20th week), our study was designed to

242 include more than two consecutive pregnancy losses and exclude those with a history of two

243 recurrent abortions to increase the selectivity of cases of chromosomal abnormalities with high

244 suspicion. Thus, the relatively high prevalence chromosomal abnormalities was found in $20.0 \%$ 
$245(5 / 25)$ of female partners and 8.0\% (2/25) of male partners, compared to other studies that found 246 chromosomal abnormalities to be common in approximately 2 to $8 \%$ of couples with RSA [26].

247 In this study, structural chromosomal abnormalities were detected in 7 patients with RPL. The 248 presence of structural chromosomal abnormalities and lack of numerical abnormalities were other findings in this study that were not predictable. The lack of numerical abnormalities in this 250 study was in contrast to the previous studies by Hanif et al. [22] from Pakistan, Ghazaey et al. [25] from Iran, and Elkarhat et al. [27] from Morocco. The structural chromosomal abnormalities encountered in this study were as follows: balanced Robertsonian translocation (2/7), unbalanced Robertsonian translocation (1/7), pericentric inversion (1/7), polymorphic variants (1/7), and addition (2/7). This study showed that Robertsonian translocation was the most prevalent chromosomal abnormality in the couples with RPL. In contrast to our findings, several studies showed that reciprocal chromosomal translocations were the most common chromosomal alterations in couples with RPL [25,26,27]. Although reciprocal chromosomal translocations were not present in this study, similar to several previous studies, the Robertsonian translocation was identified as one of the predominant aberrations in RPL cases [25,27]. Our study indicated a prevalence rate of $12.0 \%(n=3 / 25$ couples $)$ for Robertsonian translocation among patients with RPL, which was lower than previous studies from Iran (9.4\%) [25] and Morocco $(1.43 \%)$ [27]. It is estimated that 2 to $5 \%$ of couples with recurrent miscarriages carry a balanced chromosomal abnormality, which most commonly manifests as a balanced reciprocal rearrangement or Robertsonian translocation [28]. In a study by Priya et al. [28] from India, among 76 couples with RPL cases, 3.2\% $(n=5 / 152$ individuals $)$ had abnormal chromosomes, of which $4(80 \%)$ had balanced reciprocal translocations and none had Robertsonian translocations. These findings were in contrast to the results of the current research. In the present 
268

269

270

271

272

273

274

275

276

277

278

279

280

281

282

283

284

285

286

287

288

289

290

study, 3 cases of Robertsonian translocations were detected, affecting chromosomes 13, 14, and 21. About $75.0 \%$ of all Robertsonian translocations affect chromosomes 13 and 14 that are the most prevalent forms [26].

Another chromosomal abnormality found in $2 \%(n=1 / 50)$ of study participants with RPL involved pericentric inversions in chromosome 9. Several studies have shown an association between inversion 9 and infertility, recurrent abortions, and abnormal phenotypes [25,27,29]. However, the prevalence rate of inversion in this study was lower than previous studies from Iran (31.8\%) [25] and Morocco (4.3\%) [27].

In this study, statistical analysis revealed that there was a direct significant correlation between the number of RPL and the age of the female partners, and the likelihood of abortion increased with age.. This finding was in contrast to a previous study from Pakistan [22] but in line with a study from China [30]. Further, scientists believe that marriage and pregnancy of a mother at older age increase the risk of abortion, fetal and chromosomal problems, and pregnancy-related complications. Therefore, it is recommended that pregnant women of older age should undergo regular checkups and tests on natural fetal development [31]. Like our study, Jisha, et al. [32], also concluded in their study that the couples who reported for RPL had higher percentage of abnormal karyotypes. The abnormal karyotype was higher in couples with older age, longer duration of marriage, higher number of pregnancies, and higher number of spontaneous abortions.

To the best of our knowledge, there are few studies that have investigated the level of immunologic factors in the Iraqi RPL population. A strength of the current study was to evaluate the levels of various immunological factors to find an association between RPL and these markers in Iraqi patients. The results revealed that all immunological factors including 
291 antiphospholipid (IgG, IgM), anticardiolipin (IgG, IgM), lupus anticoagulant, and IL-6 were

292 within the normal range in both RPL and control groups and no test was abnormal. There were

293 no significant differences between two groups, suggesting an association between elevated

294 immunological factors and RPL cases. In contrast to these findings, a previous study by Jabber

295 et al. [33] from Iraq, showed a highly significant increase in antiphospholipid, anticardiolipin,

296 and lupus anticoagulant concentration in females with recurrent miscarriages compared to the

297 control group. Also, Drozdzik et al. [15], reported that patients with spontaneous miscarriage

298 had significantly higher levels of IL-6 in their blood serum than those with physiological

299 pregnancy. Similarly, Al-Sherbeny et al. [34] from Egypt showed a significantly higher serum

300 level of IL-6 in women with RPL than in the control group. In another study by Kniotek et al.

301 [35] from Poland, RPL patients had significantly lower levels of the proinflammatory cytokine

302 IL-6 compared to healthy women. In another study from Iraq, in line with our study, no

303 significant differences in the IL-6 levels were found between women with miscarriage and 304 control groups [36].

\section{Conclusions}

306 This study revealed a high prevalence of chromosomal abnormalities in Iraqi couples with RPL compared to other countries. Robertsonian translocation was the most common chromosomal abnormality. All chromosomal abnormalities were structural and no numerical aberrations were detected. Chromosomal analysis is a necessary component of etiologic research in couples with recurrent miscarriages. Since identifying genetic causes of miscarriages is important for genetic counseling and educating couples about the risk of future pregnancies, it is recommended that conventional karyotyping be evaluated in patients with RPL in Iraq. Finally, no significant differences in the levels of antiphospholipid, anticardiolipin, lupus anticoagulant, and IL-6 were 
314 found between RPL patients and the control group in this study. One of the limitations of this

315

316

317

318

319

320

321

322

323

324

325

326

327

328

329

330

331

332

333

334

335

336

337

338

339

340

341

342

343

344

345

346

347

348

349

350

351

study was the small sample size due to traffic restrictions caused by the coronavirus disease 2019 (COVID-19) pandemic. Therefore, it is recommended to perform this study in more regions and with a larger sample size of the country in order to confirm or reject the obtained results. Another limitation was the lack of assay for other immunological factors including natural killer cells (NK-cells), regulatory $\mathrm{T}$ cell (Treg), dendritic cells, plasma cells, and human leukocyte antigen.Acknowledgements

None.

\section{References}

[1] Bashiri A, Halper, KI, Orvieto R. Recurrent implantation failure-update overview on etiology, diagnosis, treatment nd future directions. Reprod Biol Endocrinol 2018;16:121.

[2] El Hachem H, Crepaux V, May-Panloup P, Descamps P, Legendre G, Bouet PE. Recurrent pregnancy loss: current perspectives. Int J Womens Health 2017;9:331-45.

[3] Abbas R, Ghaloub A, Ali A, Mutr A, Khyoun S, Hameed A, Mosa N. Cytogenetic and hematological study for some Iraqi women suffer from abortion. Plant Archives 2018;18(1):90107 .

[4] Alves C, Rapp A. Spontaneous Abortion. [Updated 2021 Jul 20]. In: StatPearls [Internet]. Treasure Island (FL): StatPearls Publishing; 2021 Jan-. Available from: https://www.ncbi.nlm.nih.gov/books/NBK560521/

[5] Antonette T. Spontaneous abortion (Miscarriage). Main Line Health System. MSD Manual Professional Version: The trusted provider of medical information since 1899. Last full review/revision Oct 2020.

[6] American College of Obstetricians and Gynecologists' Committee on Practice BulletinsGynecology. ACOG Practice Bulletin No. 200: Early Pregnancy Loss. Obstet Gynecol 2018; 132(5):e197-e207.

[7] Fadhil S and Ali R. Environmental effects on women's with spontaneous abortion. Journal of Kufa for Nursing Science 2014; 4(1): 1-12.

[8] Al-Qaisi M, Al-Ouqaili MT, Al-Hadithi D. Molecular analysis for azoospermia factor microdeletions in the $\mathrm{Y}$ chromosome for azoospermic and severe oligospermic infertile Iraqi patients. Sys Rev Pharm 2020;11(8):562-70. 
[9] Pokale Y, Khadke P. Cytogenetic studies of recurrent miscarriage. A review. Int STD Res Rev 2016; 4(1): 1-18.

[10] Najafi K, Gholami S, Moshtagh A, Bazrgar M, Sadatian N, Abbasi G, Rostami P, Khalili S, Babanejad M, Nourmohammadi B, Faramarzi Garous N.. Chromosomal aberrations in pregnancy and fetal loss: Insight on the effect of consanguinity, review of 1625 cases. Mol Genet Genomic Med 2019;7(8): e820.

[11] Petrova-Tacheva V, Alekova S, Popov B, Ivanov V. Cytogenetic analysis of couples with repeated spontaneous abortions. Trakia J Sci 2014; 12(1): 238-40.

[12] Najafipour R, Ansari J, Jalilvand M, Moghbelinejad S. Cytogenetic evaluation of couples with spontaneous abortion, still birth and recurrent miscarriage in Qazvin. Biotech Health Sci 2016; 3(4): 1-6.

[13] Rodrigues VD, Soligo AD, Pannain GD. Antiphospholipid antibody syndrome and infertility. Rev Bras de Ginecol e Obstet 2019;41:621-27.

[14] Omere C, Richardson L, Saade GR, Bonney EA, Kechichian T, Menon R. Interleukin (IL)6: A friend or foe of pregnancy and parturition? Evidence from functional studies in fetal membrane cells. Front Physiol 2020;11:891.

[15] Drozdzik M, Szlarb N, Kurzawski M. Interleukin-6 level and gene polymorphism in spontaneous miscarriage. Tissue Antigens 2013;82(3):171-76.

[16] Salih D, Ahmed H, Abdulmale I, Alasady A. Cytogenetic study in women with recurrent spontaneous miscarriage in Duhok Province- Iraq. International Health Sciences Conference (IHSC 2018.

[17] McGowan-Jordan J, Hastings RJ, Moore S. ISCN (An International System for Human Cytogenomic Nomenclature). Karger Publisher, 2020, $1^{\text {st }}$ Edition.

[18] Al-Ouqaili MTS, Jal'oot A, Badawy AS Identification of an OprD and bla IMP genemediated carbapenems resistance in Acinetobacter baumannii and Pseudomonas aeruginosa among patients with wound infections in Iraq. Asian Journal of Pharmaceutics 2018;12 (3): S959.

[19] Montazeri EA, Khosravi AD, Saki M, Sirous M, Keikhaei B, Seyed-Mohammadi S. Prevalence of extended-spectrum beta-lactamase-producing Enterobacteriaceae causing bloodstream infections in cancer patients from southwest of Iran. Infect Drug Resist 2020;13:1319-26.

[20] Hardy PJ, Hardy K. Chromosomal instability in first trimester miscarriage: a common cause of pregnancy loss? Transl Pediatr 2018;7(3):211-18.

[21] Agenor A, Bhattacharya S. Infertility and miscarriage: common pathways in manifestation and management. Women's Health 2015;11(4):527-41.

PeerJ reviewing PDF | (2021:10:66832:1:1:NEW 18 Dec 2021) 
401

402

403

404

405

406

407

408

409

410

411

412

413

414

415

416

417

418

419

420

421

422

423

424

425

426

427

428

429

430

431

432

433

434

435

436

437

438

439

440

441

442

443

444

445

446

447

448

449

450

451

452

453
[22] Hanif MI, Khan A, Arif A, Shoeb E. Cytogenetic investigation of couples with recurrent spontaneous miscarriages. Pak J Med Sci 2019;35(5):1422-27.

[23] Marqui AB. Chromosomal abnormalities in recurrent miscarriages by conventional karyotyping analysis. Rev Bras Saude Mater Infant 2018;18(2):265-76.

[24] Narooie-Nejad M, Nezam-Abadi S, Ranaei M, Bagherzade-Yazdi M, Mokhtari M. Study of chromosomal abnormalities in couples with recurrent miscarriage in Zahedan, Iran, Gene Cell Tissue. 2017;4(2):e55355.

[25] Ghazaey S, Keify F, Mirzaei F, Maleki M, Tootian S, Ahadian M, et al. Chromosomal analysis of couples with repeated spontaneous abortions in northeastern iran. Int J Fertil Steril 2015;9(1):47-54.

[26] Fan H, Zhang M, Zhan P, Yang X, Tian W, Li R. Structural chromosomal abnormalities in couples in cases of recurrent spontaneous abortions in Jilin Province, China. Genet Mol Res 2016;15(1):1-7.

[27] Elkarhat Z, Kindil Z, Zarouf L, Razoki L, Aboulfaraj J, Elbakay C, Nassereddine S, Nasser B, Barakat A, Rouba H.. Chromosomal abnormalities in couples with recurrent spontaneous miscarriage: a 21-year retrospective study, a report of a novel insertion, and a literature review. J Assist Reprod Genet 2019;36(3):499-507.

[28] Priya PK, Mishra VV, Roy P, Patel H. A Study on balanced chromosomal translocations in couples with recurrent pregnancy loss. J Hum Reprod Sci 2018;11(4):337-42.

[29] Abdi A, Bagherizadeh I, Shajare pour L, Bahman I, Hadi pour Z, Hadi pour F, Shafaghti Y, Behjati F. Prevalence of chromosome inversions (pericentric and paracentric) in patients with recurrent abortions. Sarem J Med Res. 2018; 3(1):45-50.

[30] Sheng YR, Hou SY, Hu WT, Wei CY, Liu YK, Liu YY, Jiang L, Xiang JJ, Sun XX, Lei $\mathrm{CX}$, Wang HL. Characterization of copy-number variations and possible candidate genes in recurrent pregnancy losses. Genes 2021;12(2):141.

[31] Moradinazar M, Najafi F, Nazar ZM, Hamzeh B, Pasdar Y, Shakiba E. Lifetime Prevalence of Abortion and Risk Factors in Women: Evidence from a Cohort Study. J Pregnancy 2020;2020:4871494.

[32] Jisha P, Sanuj C, Dinesh Roy D. Cytogenetic analysis of couples with recurrent pregnancy loss. Int J Sci Engin Res 2014;5(7):1107-13.

[33] Jabber YM, Hassan AJ, Abdullah HN. Assessment of some biomarkers related with recurrent miscarriages in Iraq. Sys Rev Pharm 2020;11(9):156-62.

[34] Al-Sherbeny MF, Hassaan MM. Disturbed inflammatory/anti-inflammatory milieu and activation of primary phase reactants may underlie development and recurrence of first trimester pregnancy loss. Bull Egypt Soc Physiol Sci 2017;37(2):189-98.

[35] Kniotek M, Zych M, Roszczyk A, Szafarowska M, Jerzak MM. Decreased production of TNF- $\alpha$ and IL-6 inflammatory cytokines in non-pregnant idiopathic RPL women immunomodulatory effect of sildenafil citrate on the cellular response of idiopathic RPL women J Clin Med. 2021;10(14):3115. 
454 [36] Abdullah GA, Mahdi NK. The role of cytokines among women with spontaneous 455 miscarriage. Med J Islamic World Acad Sci 2013;21(3):119-24.

456

457

458

459

460 


\section{Table 1 (on next page)}

Karyotyping findings in the couples with history of recurrent pregnancy loss. 


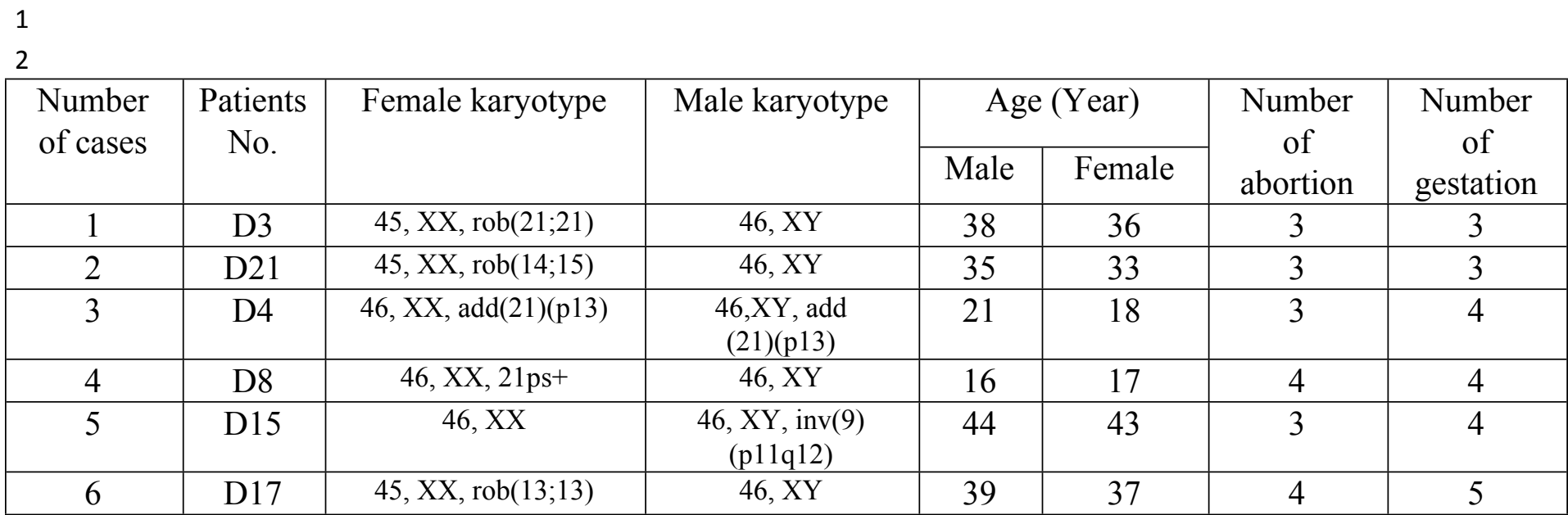

3

4

5

6

7

8

9

10

11

12

13

14

15

16

17

18

19 


\section{Table 2 (on next page)}

The distribution of the values of anti-phospholipid (APL) (IgG and IgM), anti-cardiolipin (IgG and $\lg M$ ), lupus anticoagulant (LA), and interleukin-6 among the females with recurrent pregnancy loss. 


\begin{tabular}{|c|c|c|c|c|c|c|c|c|c|}
\hline Patient no. & $\begin{array}{l}\text { Age of female } \\
\text { partner }\end{array}$ & $\begin{array}{c}\text { Age of male } \\
\text { partner }\end{array}$ & Karyotyping & $\begin{array}{c}\text { LA } \\
\text { Normal range } \\
(31-41 \text { sec) }\end{array}$ & $\begin{array}{c}\text { APL IgG } \\
\text { Normal range } \\
(\leq 10 \mathrm{GPH}-\mathrm{U} / \mathrm{ml})\end{array}$ & $\begin{array}{c}\text { APL IgM } \\
\text { Normal range } \\
(\leq 7 \mathrm{MPH}-\mathrm{U} / \mathrm{ml})\end{array}$ & $\begin{array}{c}\text { Anticardiolipin } \\
\text { IgG } \\
\text { Normal range } \\
\text { ( } \leq 10 \text { GPH-U/ml) } \\
\end{array}$ & $\begin{array}{c}\text { Anticardiolipin } \\
\text { IgM } \\
\text { Normal range } \\
\text { ( } \leq 7 \mathrm{MPH}-\mathrm{U} / \mathrm{ml} \text { ) } \\
\end{array}$ & $\begin{array}{c}\text { IL-6 } \\
\text { Normal range } \\
(\leq 7 \mathrm{pg} / \mathrm{ml})\end{array}$ \\
\hline D1 & 21 & 27 & Normal & 26.5 & 0.4 & 0.2 & 0.2 & 0.4 & 1.0 \\
\hline D2 & 39 & 46 & Normal & 31.5 & 0.3 & 0.1 & 0.1 & 0.2 & 1.3 \\
\hline D3 & 36 & 38 & $\underline{\text { Abnormal }}$ & 32.0 & 0.1 & 0.2 & 0.2 & 0.4 & 1.4 \\
\hline D5 & 25 & 29 & Normal & 27.5 & 0.6 & 0.2 & 0.3 & 0.4 & 1.0 \\
\hline D6 & 36 & 39 & Normal & 31.0 & 0.2 & 0.1 & 0.4 & 0.5 & 1.5 \\
\hline D7 & 31 & 35 & Normal & 32.0 & 0.4 & 0.4 & 0.2 & 0.3 & 1.5 \\
\hline D10 & 39 & 42 & Normal & 33.0 & 0.4 & 0.1 & 0.3 & 0.1 & 1.8 \\
\hline D11 & 28 & 30 & Normal & 34.0 & 0.5 & 0.2 & 0.2 & 0.7 & 1.6 \\
\hline D12 & 23 & 28 & Normal & 33.0 & 0.7 & 0.2 & 0.3 & 0.6 & 1.5 \\
\hline D13 & 37 & 41 & Normal & 30.0 & 0.3 & 0.6 & 0.3 & 0.2 & 2.0 \\
\hline D14 & 27 & 28 & Normal & 35.0 & 0.1 & 0.4 & 0.1 & 0.3 & 1.8 \\
\hline
\end{tabular}




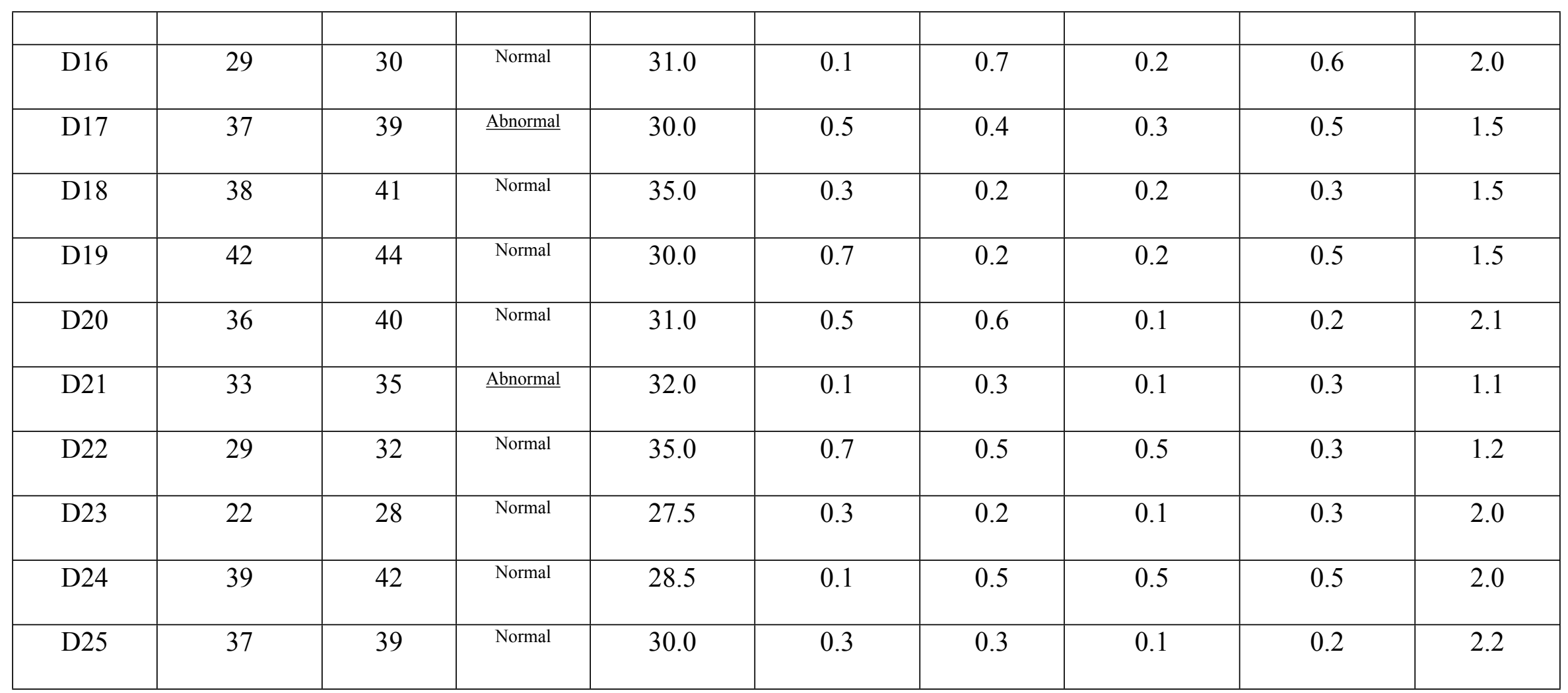




\section{Table 3 (on next page)}

Comparison of anticardiolipin (IgG and $\lg M$ ), antiphosopholipid (IgG and $\lg M$ ), lupus anticoagulant, and IL-6 levels in the females with RPL and healthy females in control group. 


\begin{tabular}{|c|c|c|c|c|c|}
\hline parameters & $\begin{array}{c}\text { Study Cases/ } \\
\text { Control }\end{array}$ & Number & Mean & Std. Deviation & $\begin{array}{c}P \text {-Value } \\
\text { Sig. (2-tailed) }\end{array}$ \\
\hline \multirow[t]{2}{*}{ Lupus anticoagulant } & Case & 25 & 31.360 & 2.4855 & \multirow[t]{2}{*}{0.287} \\
\hline & Control & 25 & 30.688 & 1.8833 & \\
\hline \multirow[t]{2}{*}{ Antiphospholipid (IgG) } & Case & 25 & 0.372 & 0.2092 & \multirow[t]{2}{*}{0.395} \\
\hline & Control & 25 & 0.324 & 0.1855 & \\
\hline \multirow[t]{2}{*}{ Antiphospholipid (IgM) } & Case & 25 & 0.316 & 0.1886 & \multirow[t]{2}{*}{0.083} \\
\hline & Control & 25 & 0.234 & 0.1365 & \\
\hline \multirow[t]{2}{*}{ Anticardiolipin (IgG) } & Case & 25 & 0.220 & 0.1225 & \multirow[t]{2}{*}{0.639} \\
\hline & Control & 25 & 0.204 & 0.1172 & \\
\hline \multirow[t]{2}{*}{ Anticardiolipin (IgM) } & Case & 25 & 0.356 & 0.1530 & \multirow[t]{2}{*}{0.086} \\
\hline & Control & 25 & 0.284 & 0.1375 & \\
\hline \multirow[t]{2}{*}{ Interleukin-6 } & Case & 25 & 1.584 & 0.3859 & \multirow[t]{2}{*}{0.30} \\
\hline & Control & 25 & 1.372 & 0.2762 & \\
\hline
\end{tabular}

1 


\section{Table 4 (on next page)}

The mean \pm standard deviation of antiphospholipid IgG and IgM, anticardiolipin IgG and IgM, lupus anticoagulant, and interleukin- 6 among the females with recurrent pregnancy loss. 
2

\begin{tabular}{|c|c|c|c|c|c|}
\hline Item & No. & $\begin{array}{c}\text { Minimum } \\
\text { values }\end{array}$ & $\begin{array}{c}\text { Maximum } \\
\text { values }\end{array}$ & Mean & $\begin{array}{c}\text { Standard } \\
\text { deviation }\end{array}$ \\
\hline Age & 25 & 18 & 44.0 & 31.92 & 7.251 \\
\hline Antiphospholipid IgG & 25 & 0.1 & 0.7 & 0.37 & 0.209 \\
\hline Antiphospholipid IgM & 25 & 0.1 & 0.7 & 0.32 & 0.189 \\
\hline Anticardiolipin IgG & 25 & 0.1 & 0.5 & 0.22 & 0.123 \\
\hline Anticardiolipin IgM & 25 & 0.1 & 0.7 & 0.36 & 0.153 \\
\hline Lupus anticoagulant & 25 & 26.5 & 35.0 & 31.36 & 2.486 \\
\hline Interleukin-6 & 25 & 1.0 & 2.2 & 1.58 & 0.386 \\
\hline
\end{tabular}

3

4

5

6

7 
Figure 1

Distribution of studied participants based on their age range.

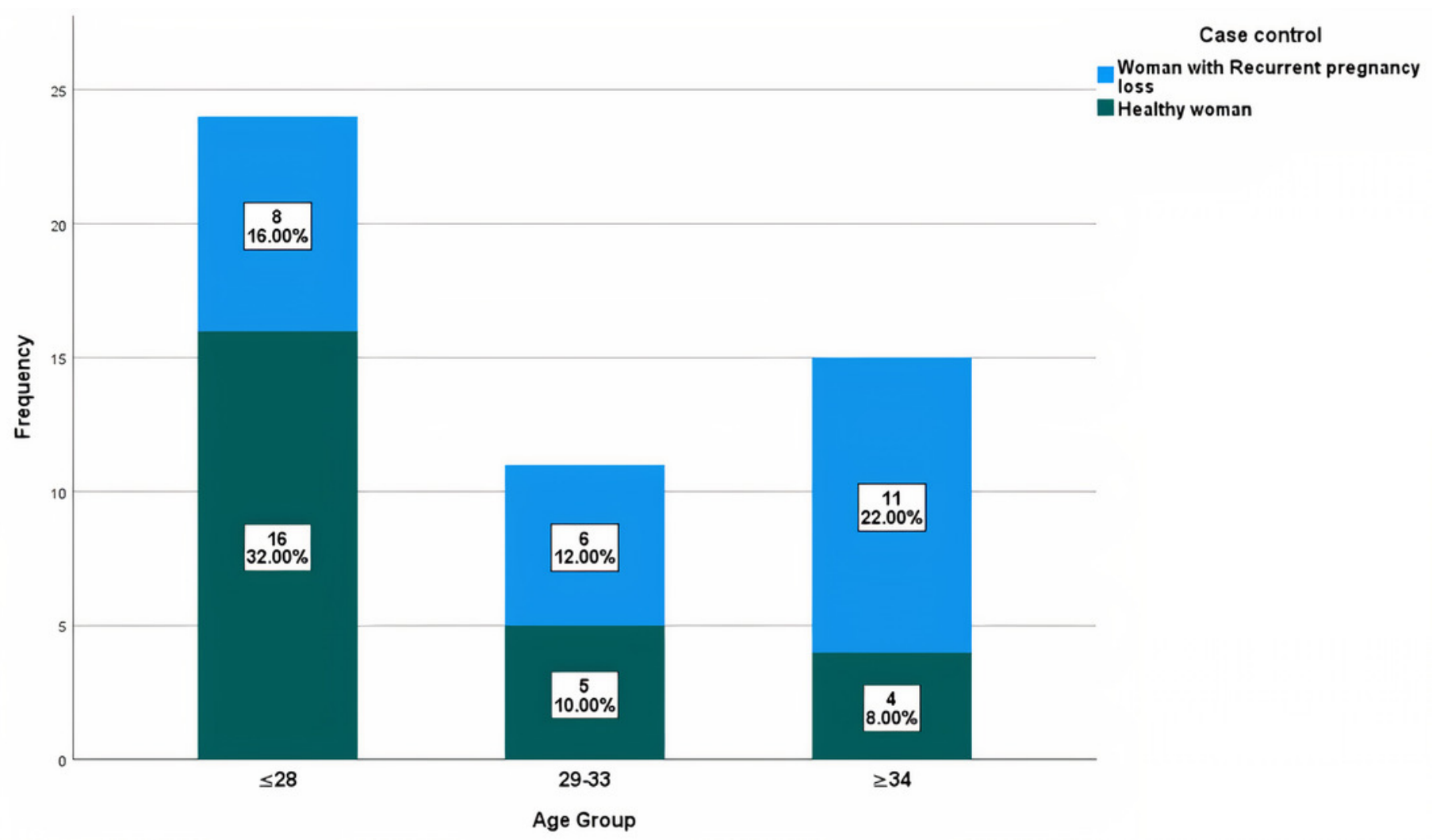


Figure 2

The significant correlation between the number of recurrent pregnancy loss and the age of the study female partners.

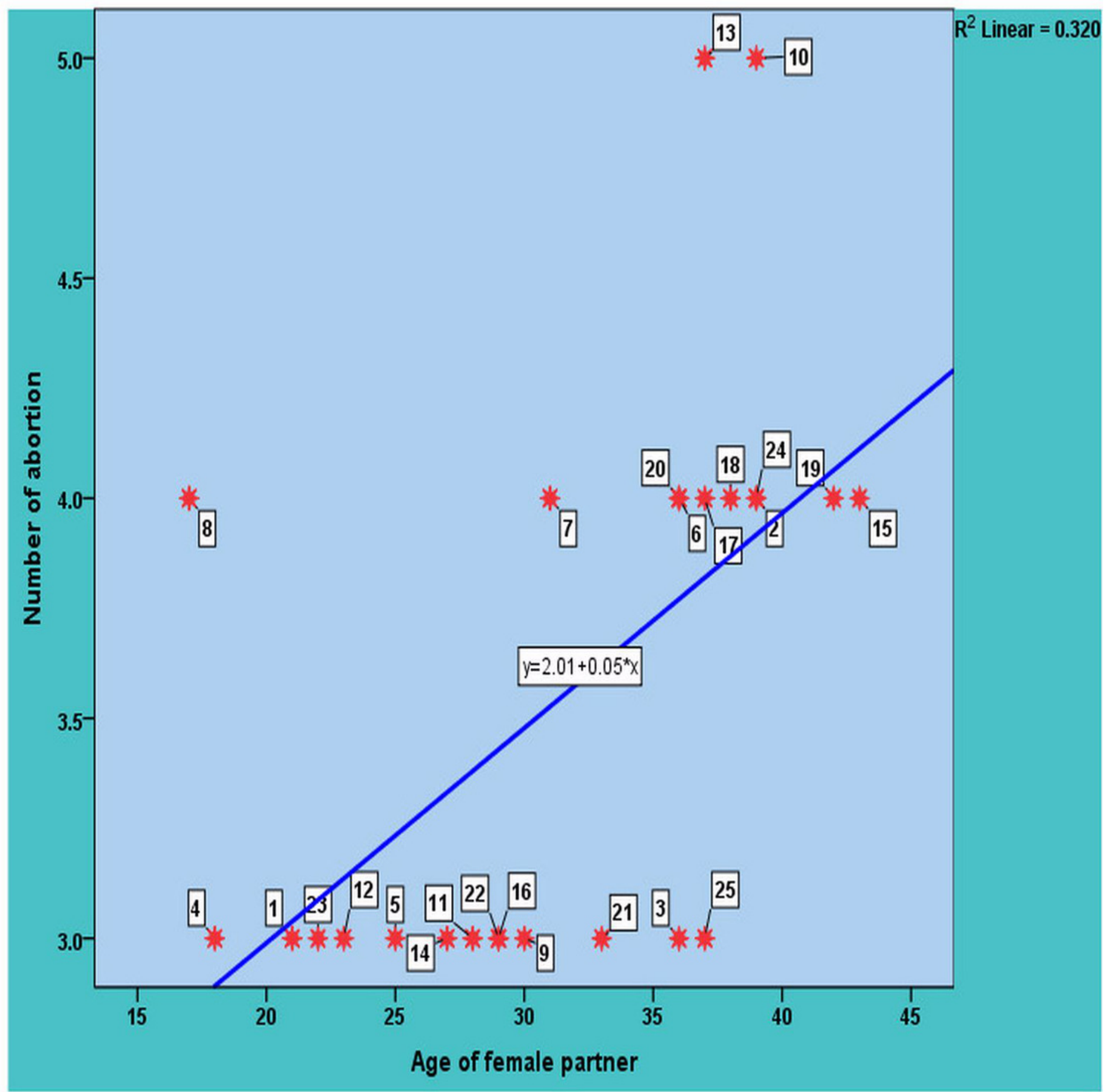


Figure 3

Karyotype of the female with $45, \mathrm{XX}, \mathrm{t}(21 ; 21)$. This case is consistent with female karyotype with Robertsonian translocation of chromosome 21.
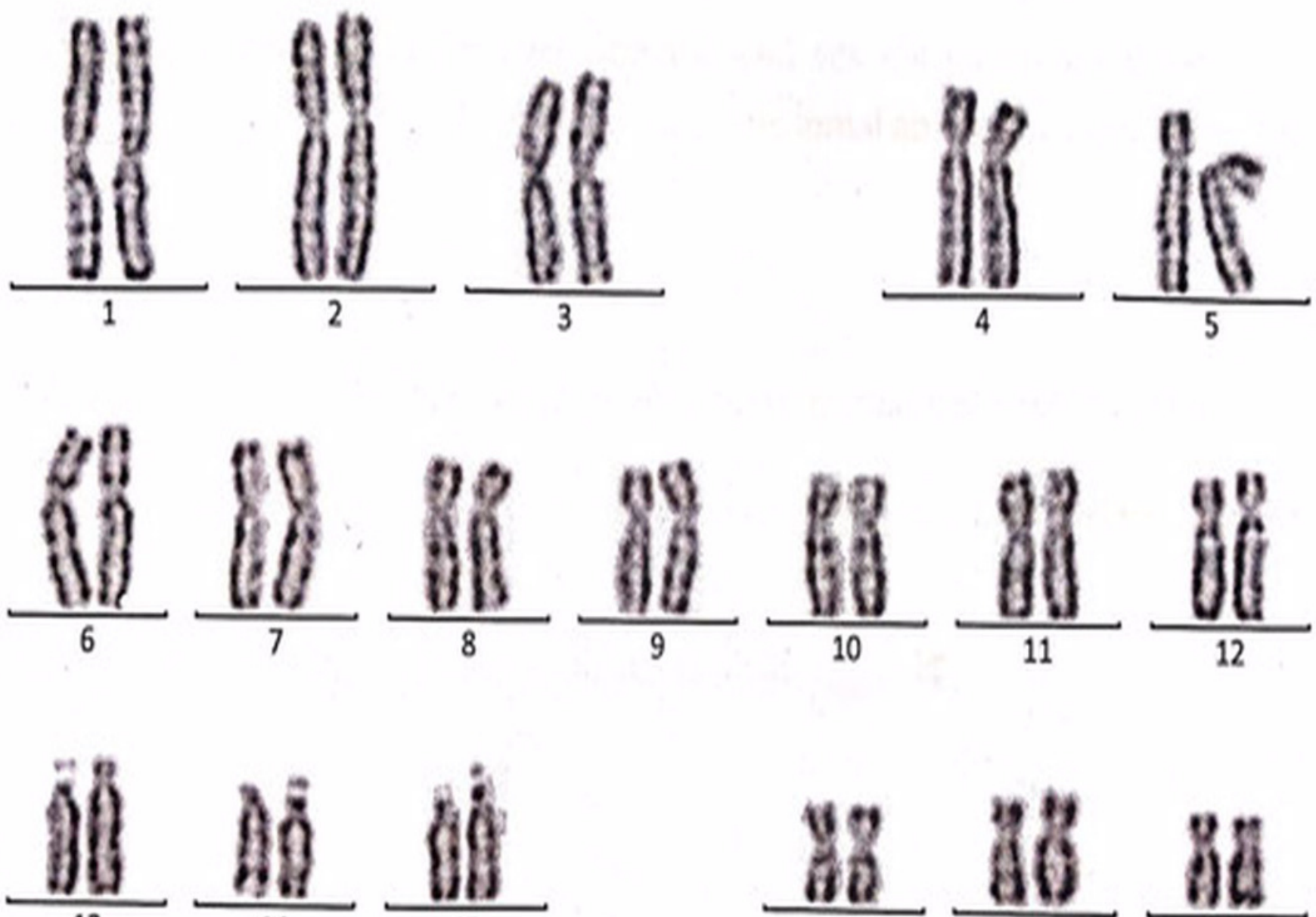

13
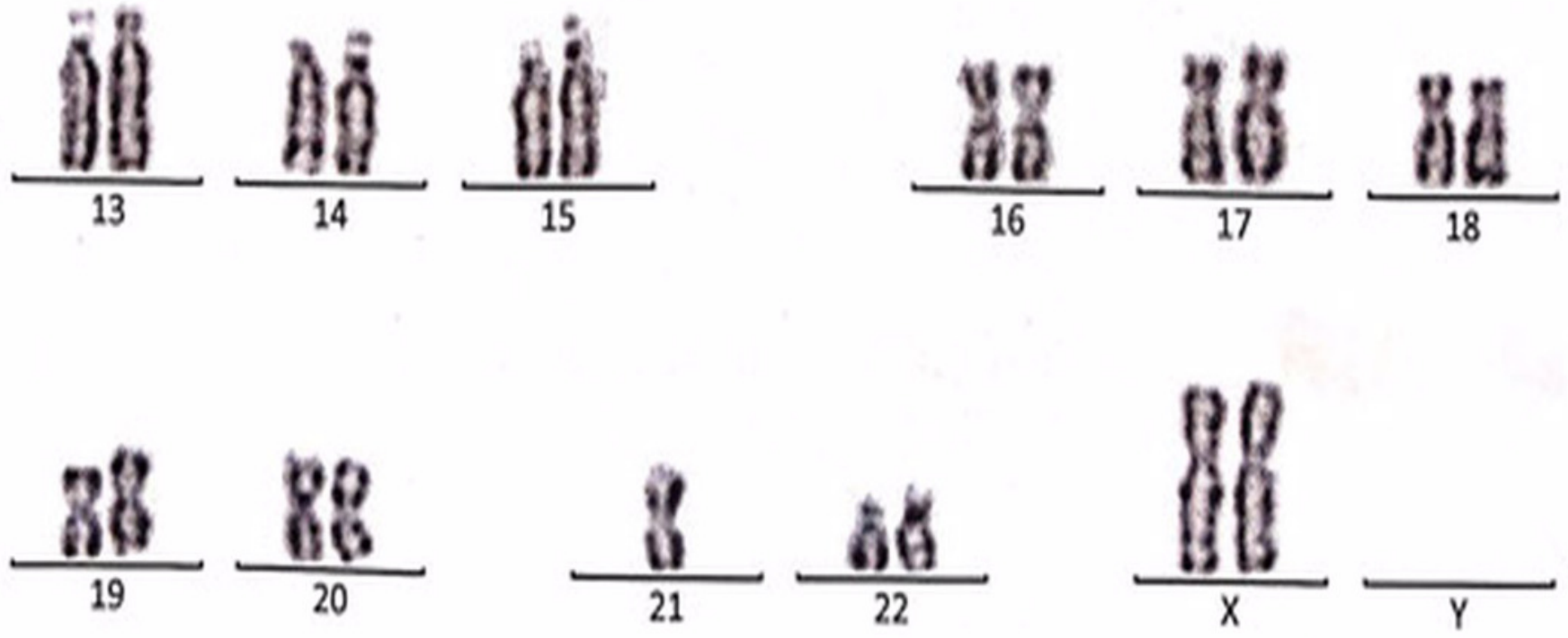
Figure 4

Karyotype of the female with $45, X X, \operatorname{rob}(14,15)$. This case is consistent with female karyotype which has a Robertsonian translocation between the long arm of chromosome 14 and the long arm of chromosome 15.
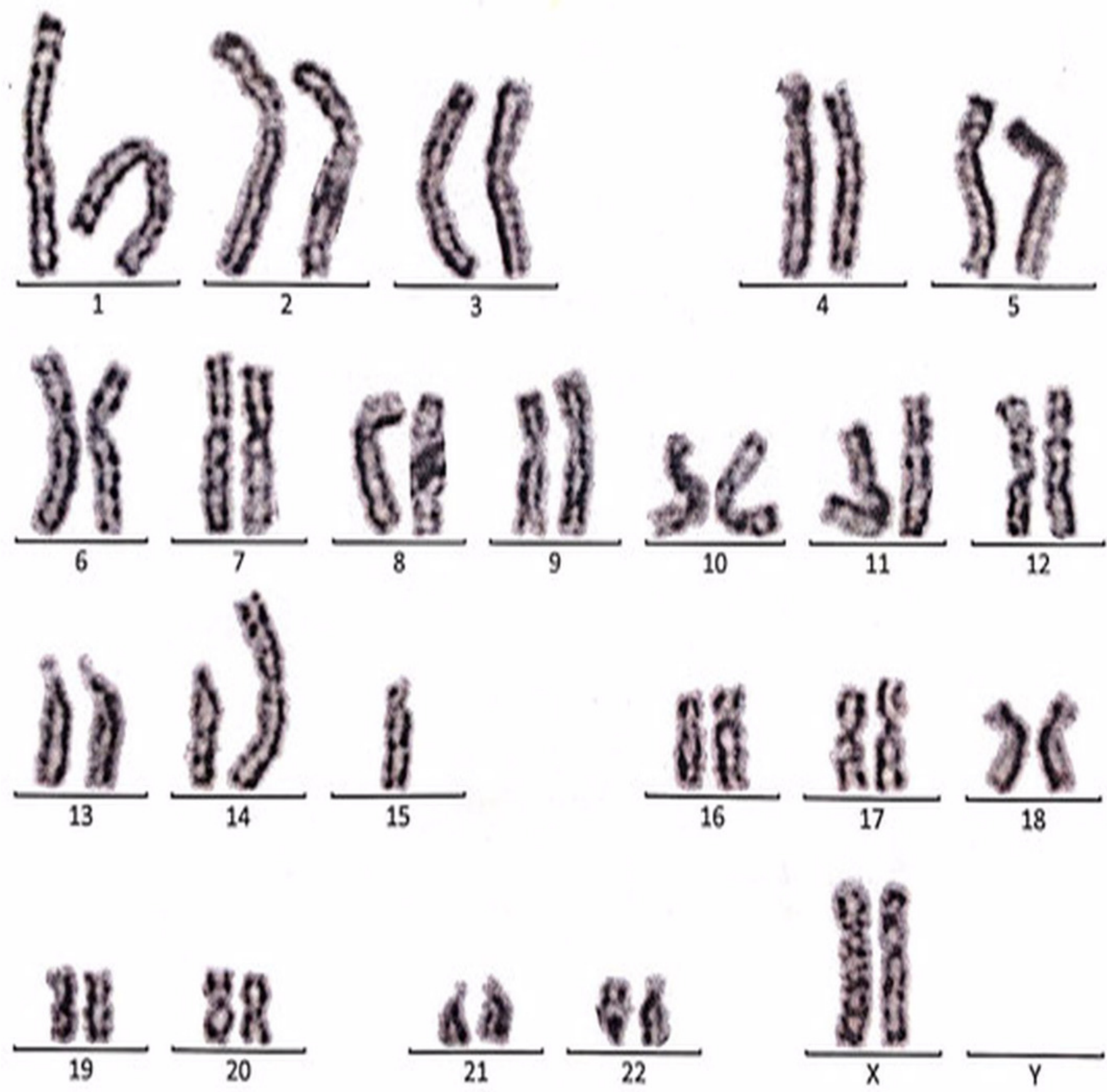
Figure 5

Karyotype of the male with $46, X Y$, add $(21)(p 13)$. This case is consistent with male karyotype which has an addition material attached to band 13 on the short arm of chromosome 21.

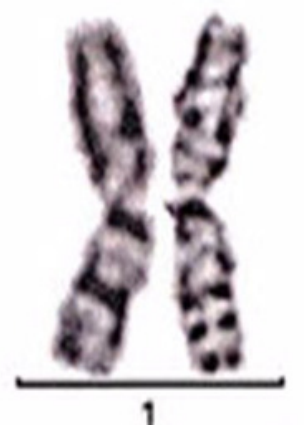

1
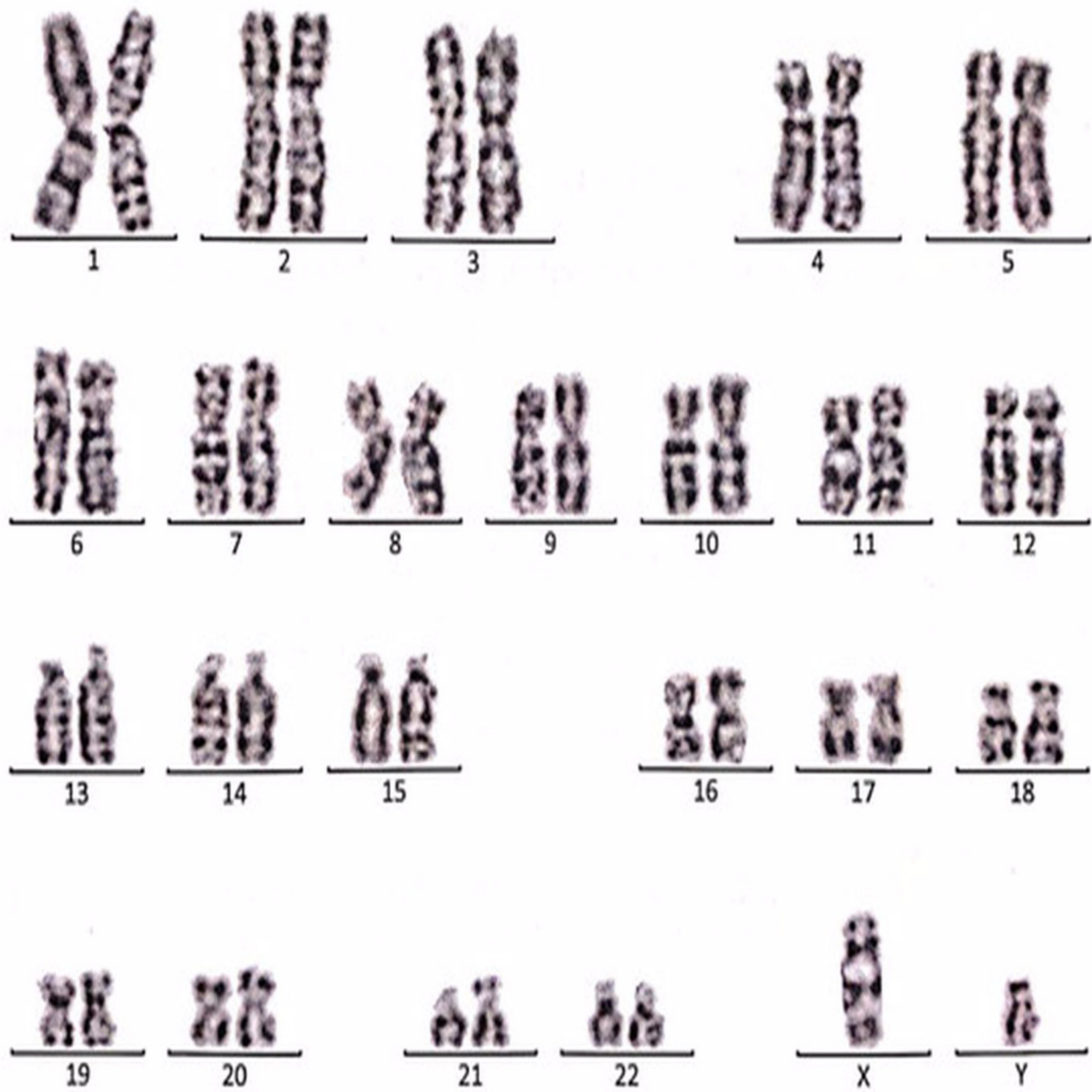
Figure 6

Karyotype of the female with $46, X X$, add $(21)$ (p13). This case is consistent with female karyotype which has an addition material attached to band 13 on the short arm of chromosome 21.
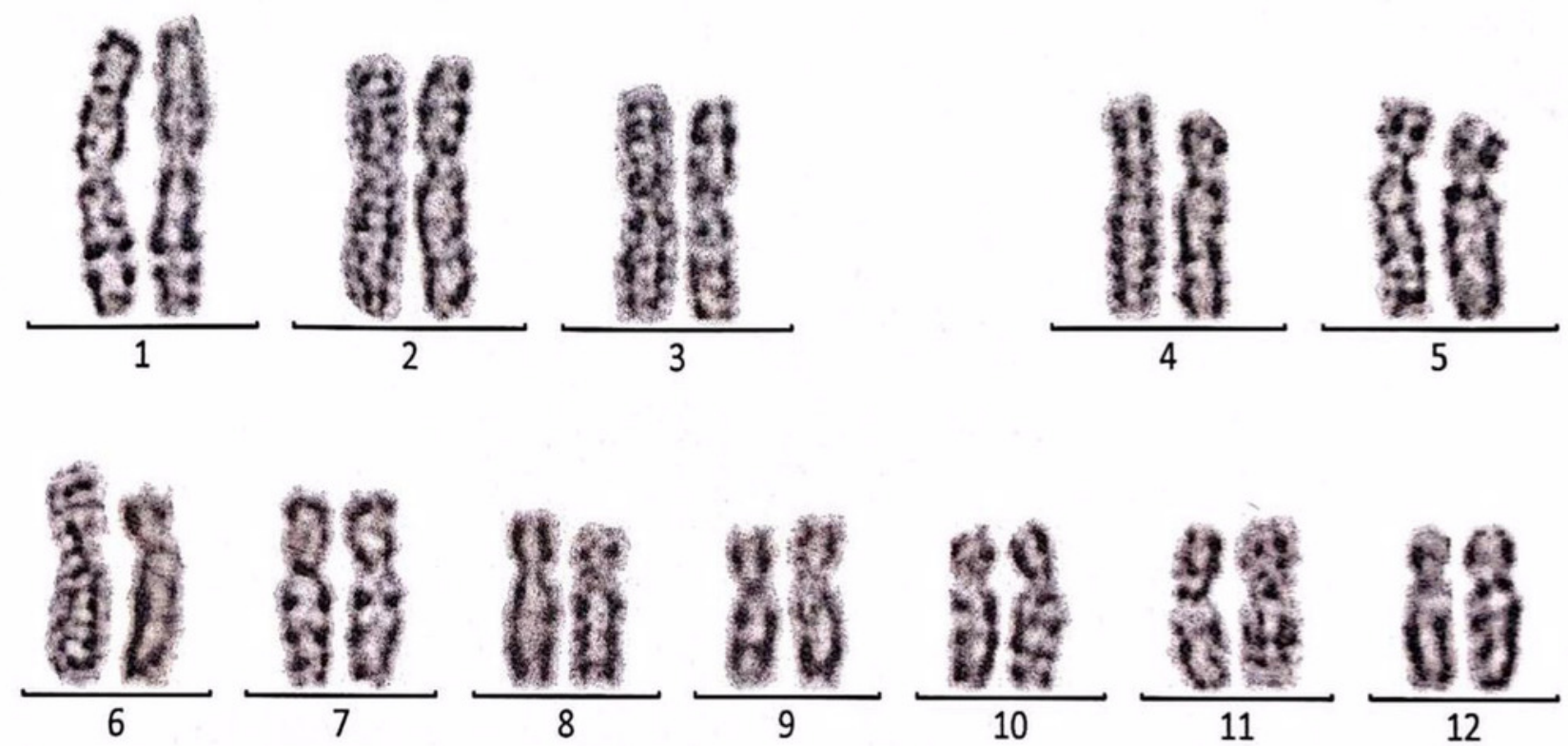

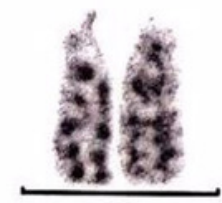

13
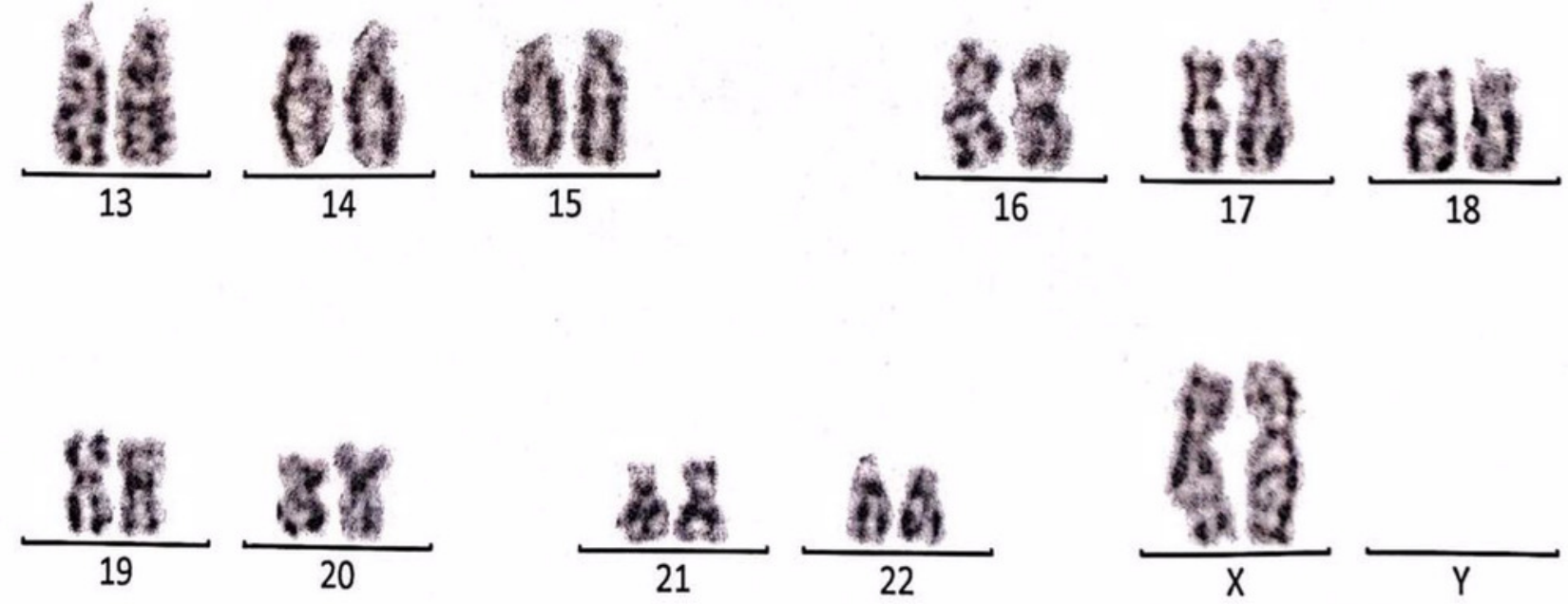
Figure 7

Karyotype of the female with $46, \mathrm{XX}, 21 \mathrm{ps}+$. This case is consistent with female karyotype which has an increase in the length of satellite on short arm of chromosome 21.
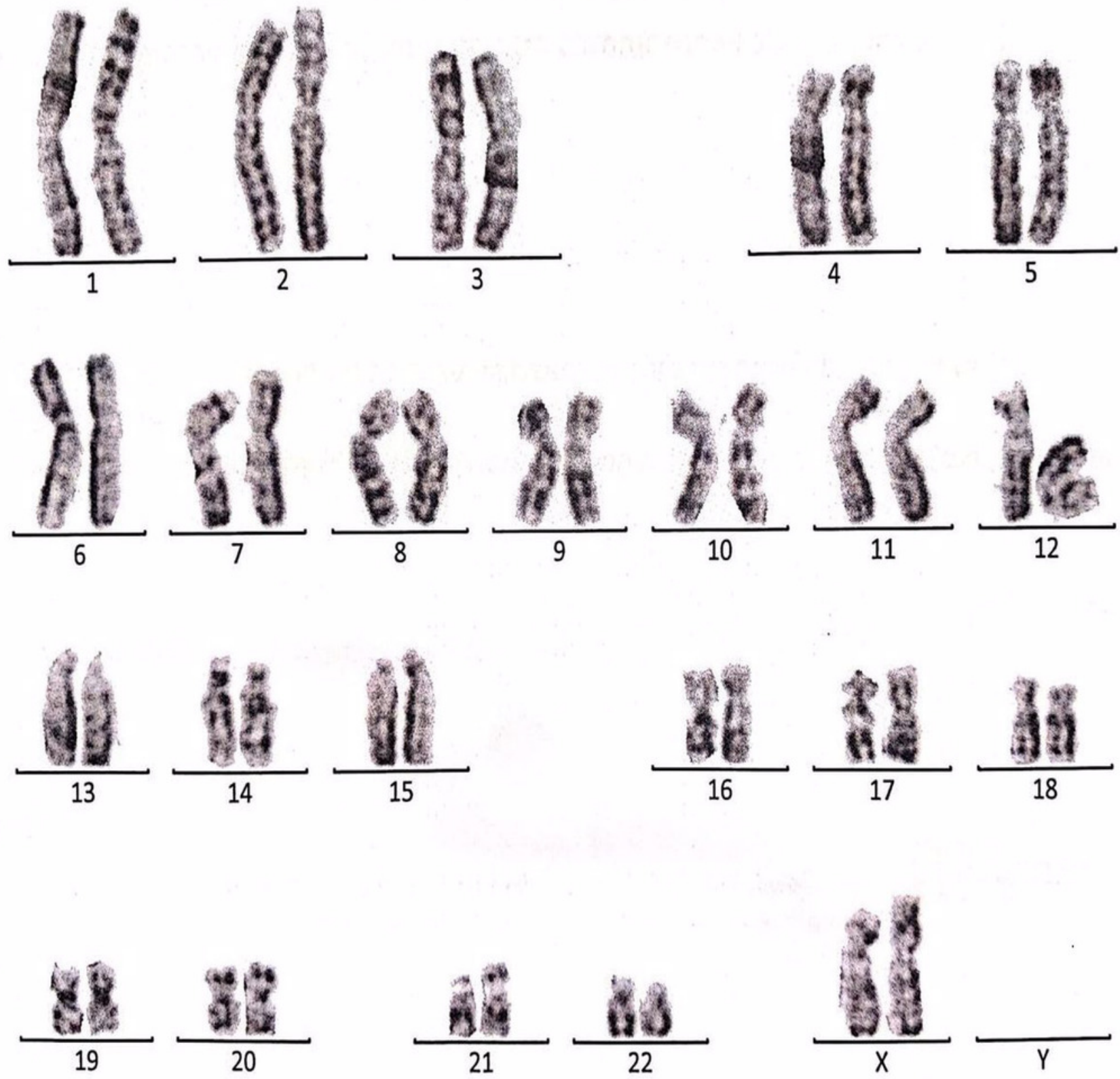
Figure 8

Karyotype of the male with 46, XY, per inv (9) (p11q12). This case is consistent with male karyotype which has percentric inversion of chromosome 9 which may be a normal variant in human being.
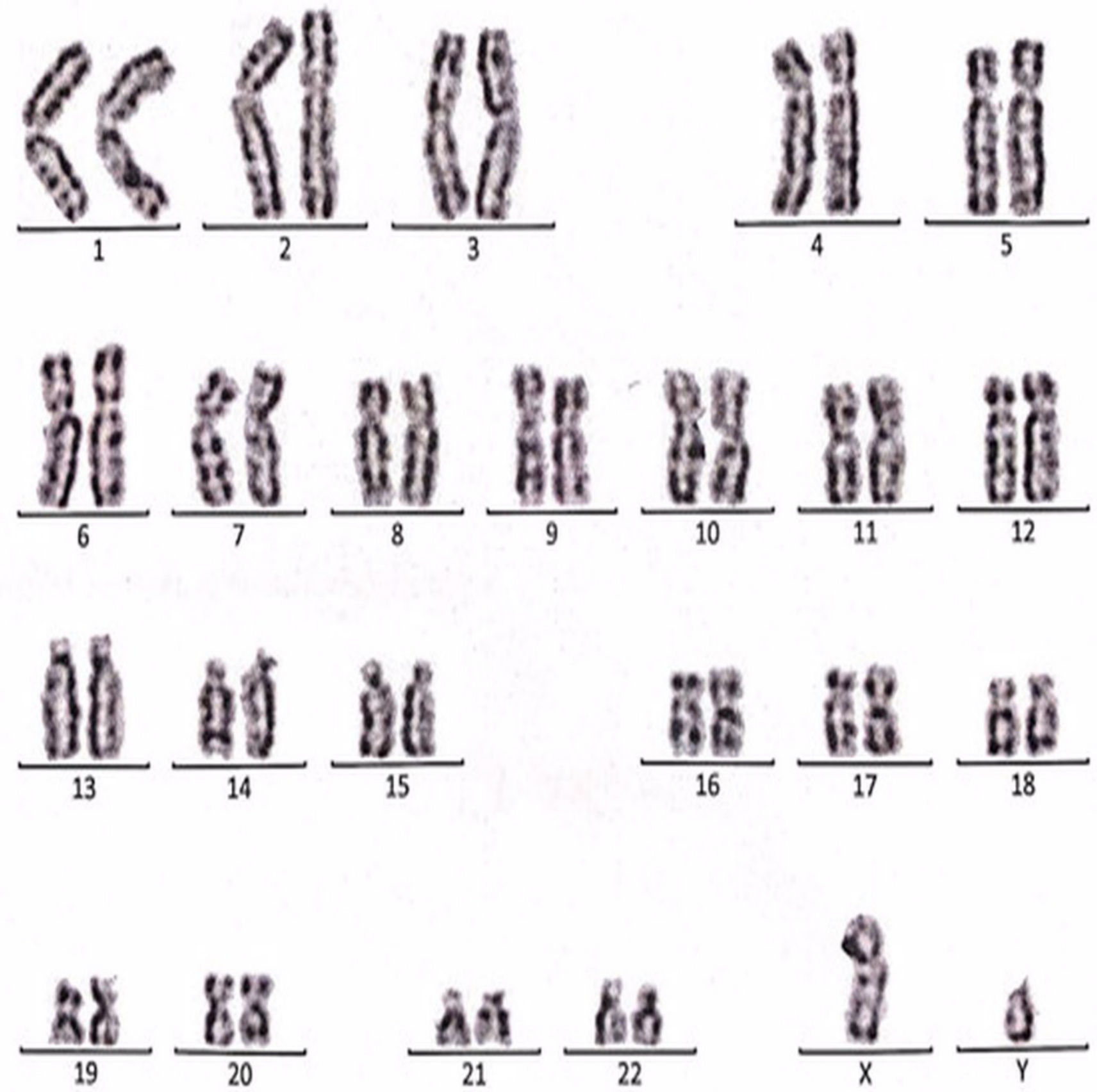
Figure 9

Karyotype of the male with $45, \mathrm{XY}, \mathrm{t}(13 q, 13 q)$. This case is consistent with male karyotype with balanced Robertsonian translocation between the long arms of both copies of chromosome 13.
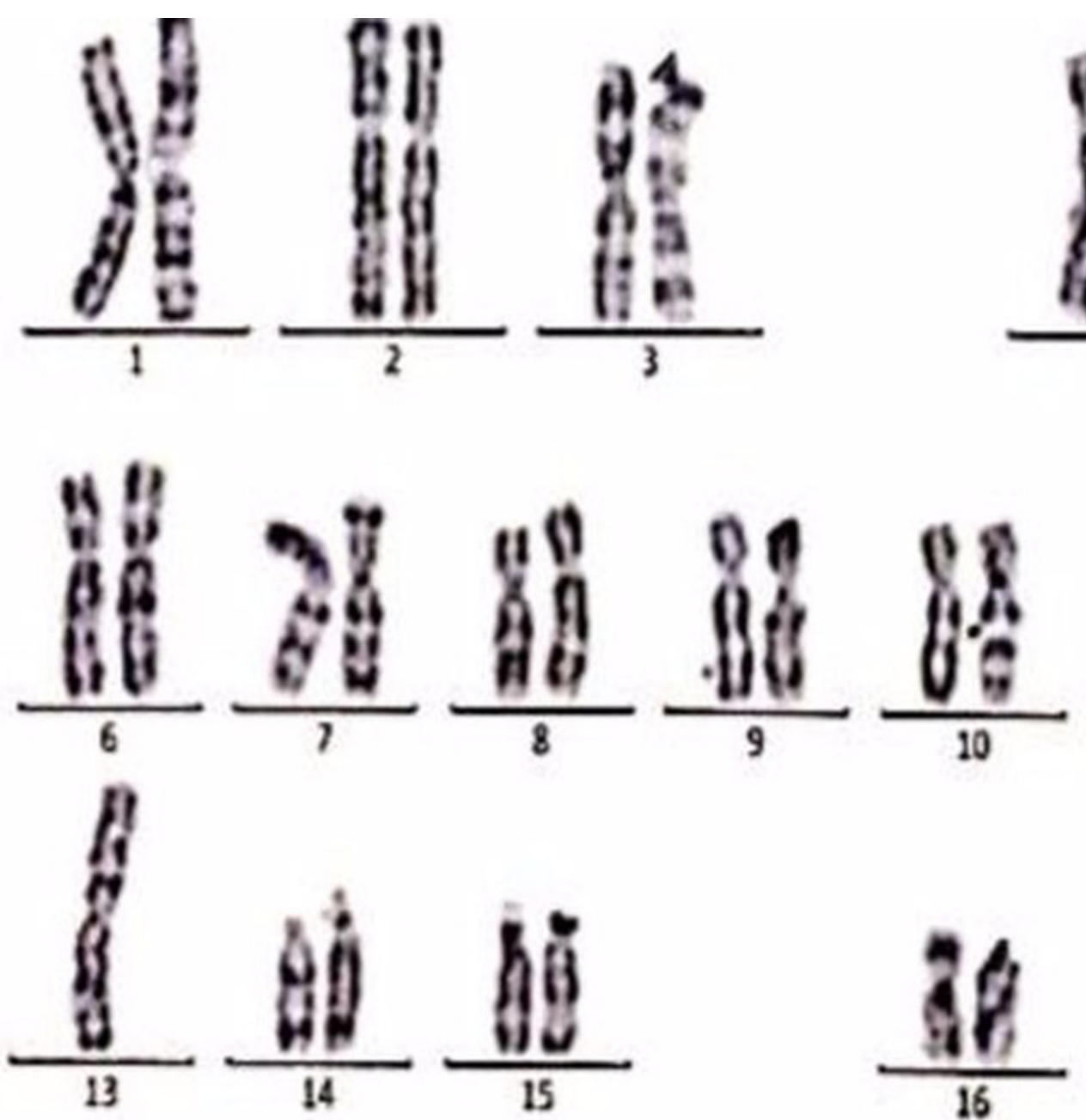

10
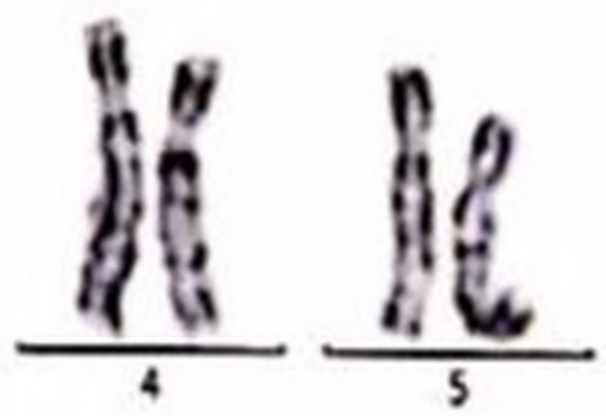
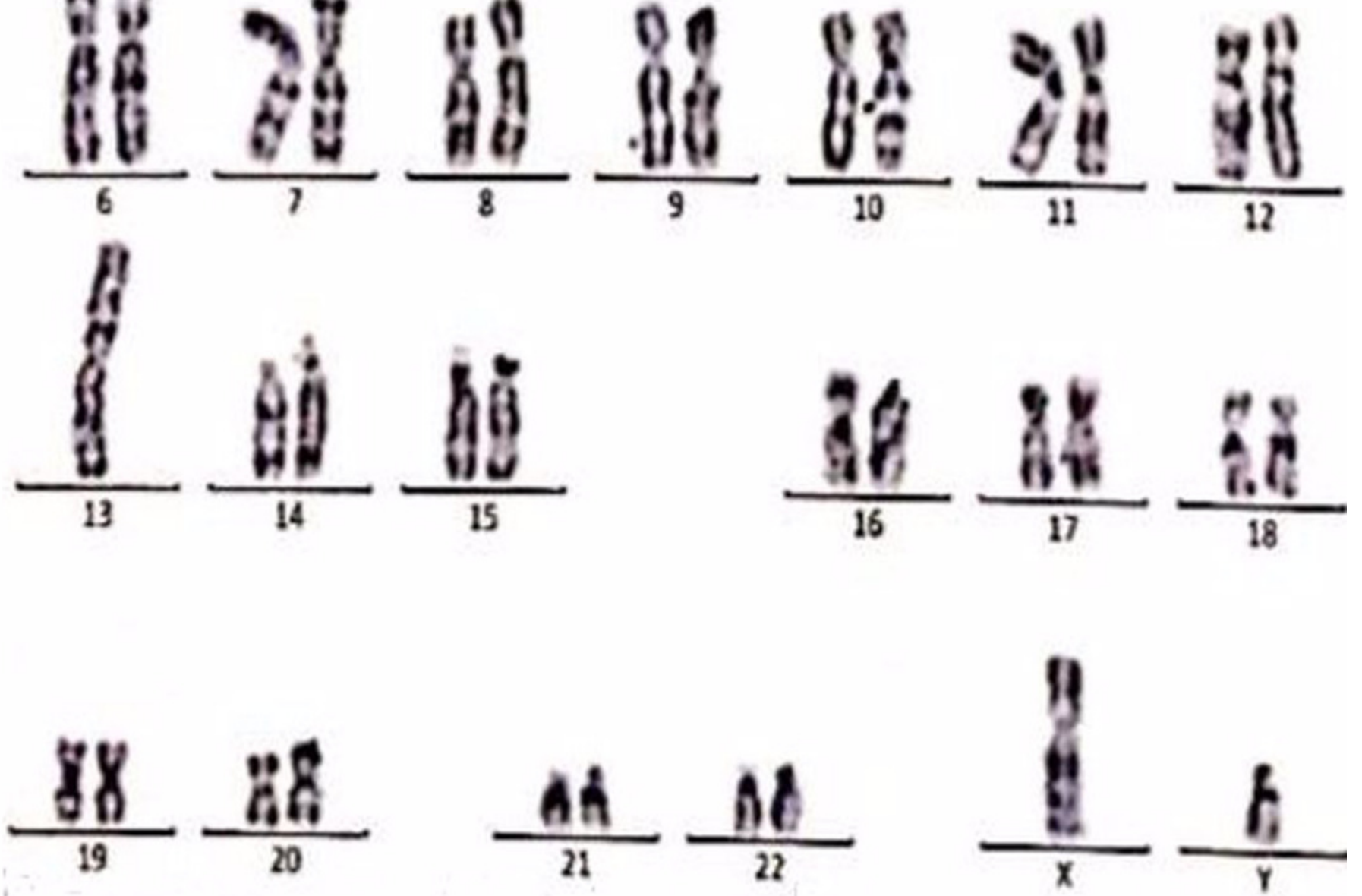
Figure 10

The mean \pm standard deviation of lupus anticoagulant, antiphospholipid IgG and IgM, anticardiolipin IgG and IgM, and interleukin-6 in the study women with recurrent pregnancy loss.

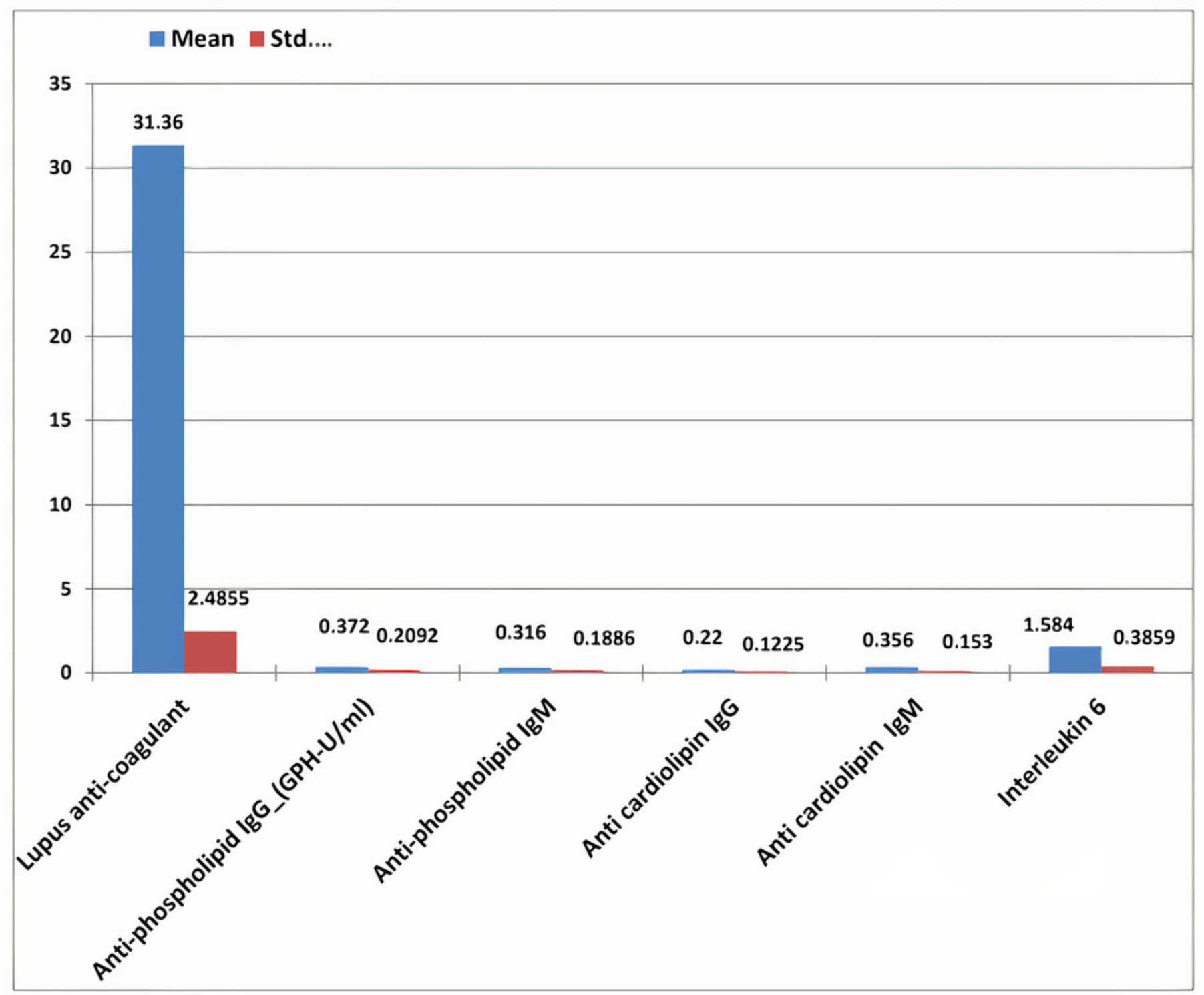

